\title{
Staphylococcus sciuri outbreak at Tertiary Hospital in Benin
}

\section{Ahoyo TA ${ }^{1 *}$, Yehouenou Pazou E1, Baba-Moussa L², Attolou Gbohou $\mathrm{A}^{3}$, Boco $\mathrm{M}^{3}$, Dramane $\mathrm{KL}^{4}$ and Aminou $\mathrm{T}^{5}$}

${ }^{1}$ Département du Génie de Biologie Humaine EPAC 01BP 2009 Cotonou, Benin

${ }^{2}$ Laboratoire de Biologie et de Typage Moléculaire en Microbiologie, Faculté des Sciences et Techniques/Université d'Abomey-Calavi, 05 BP 1604 Cotonou, Benin ${ }^{3}$ Centre Hospitalier Départemental du Zou/Collines Abomey, Benin

${ }^{4}$ Laboratoire de pharmacodynamie, FAST UAC 01 BP 526 Cotonou, Bénin

${ }^{5}$ Laboratoire d'expertise et de recherche en chimie de l'eau et de l'environnement, UAC 01 BP 526 Cotonou, Bénin

\begin{abstract}
Background: Infections due to Staphylococcus sciuri in hospitalized patients seem to be emerging in different countries. Their incidence and clinical impact with inpatients have not been studied in Benin.

Objective: The aim of this study was to estimate the prevalence of Staphylococcus sciuri during bloodstream infection and to assess the importance of the hospital environment as a possible secondary reservoir of multiresistant bacteria capable of colonizing or infecting patients.

Patients and methods: Between June and December 2008, clinical information and samples were collected from patients suspected to have nosocomial bloodstream infections at a tertiary hospital in Benin. The isolates were identified, tested for antimicrobial susceptibility. Particularly attention was paid to Staphylococcus sciuri and factors associated with the carriage. Concurrently, swabbing of environment was achieved. MALDI TOF of abundant proteins was applied to identify and to discriminate Staphylococcus sciuri isolates.
\end{abstract}

Results: Nosocomial bactereamia incidence rate was 2, 58 cases per 1000 patient-days. The proportion of Staphylococcus sciuri among coagulase negative staphylococci was $24.5 \%$ and represented $15 \%$ of the environment specimens. Catheter was the commonest source of nosocomial bacteremia $(41 \%)$. The frequency of resistance to methicillin for Staphylococcus aureus isolates was $36 \%$ and $44 \%$ for Staphylococcus sciuri isolates. Mass spectra were specific for five groups of $S$. sciuri isolates.

Conclusion: Our survey revealed a high level of Staphylococcus sciuri among Coagulase Negative Staphylococcus isolated from blood specimen. There is a need to institute strict hospital infection control policy and a regular surveillance of resistance to antimicrobial agents.

Keywords: Staphylococcus scuiri; Nosocomial bloodstream infection; Catheter

\section{Introduction}

In recent years, the Coagulase-Negative Staphylococci (CNS) has been studied extensively because of their pathogenicity and involvement in some kinds of human and animal diseases $[1,2]$. They were recognized to be a common cause of nosocomial infections and an important pathogen of bloodstream infections in the intensive care setting [2,3]. Members of the Staphylococcus sciuri (S. sciuri) group are generally considered to be bacteria of doubtful pathogenicity in human diseases [4-6]. Moreover, S. sciuri has been associated with serious infections in humans, such as endocarditis, peritonitis, septic shock, and wound infections [4-9]. It has been estimated that they may constitute 0.79 to $4.3 \%$ of the total number of CNS isolated from clinical samples in developed countries [6,9]. Furthermore, CNS are nosocomial pathogens associated with multiple antimicrobialresistance mechanisms including, in particular, methicillin resistance $[7,10]$. Surveillance is one of the key success factors for developing strategies for the understanding and for the prevention of nosocomial infections according to authors [11,12]. In May 2008, the infection control program at the Zou/Collines Hospital Center $(\mathrm{CHDZ} / \mathrm{C})$ in Benin was notified of a child hospitalized in the pediatric unit developed nosocomial bactereamia due to $S$. sciuri isolated in pure culture. The following investigation identified the first nosocomial outbreak due to S. sciuri in Benin. In the present study, we determined the frequency of $S$. sciuri isolated from blood specimen taken for diagnosis purposes at $\mathrm{CHDZ} / \mathrm{C}$ and Characterized the $S$. sciuri isolates based on antibiotyping and Potential of Matrix-Assisted Laser Desorption Ionization-TimeOf-Flight Mass Spectrometry (MALDI-TOF/MS).

\section{Patients and Methods}

\section{Study population}

A prospective study was carried out over a period of six months, from June $5^{\text {th }}$ to December $10^{\text {th }}, 2008$ at CHDZ/C a tertiary referral hospital of 500 beds, covering most medical specialties with the exception of transplant surgery in Benin. All consecutive consenting adult patients admitted to one ward of $\mathrm{CHDZ} / \mathrm{C}$ hospital center were enrolled. These patients were studied as part of a prospective evaluation of the nosocomial acquisition and transmission of microorganism during bloodstream infection. A nosocomial bactereamia is defined as a clinically important blood culture positive for a bacterium or fungus that is obtained more than 48 hours following hospitalization as described by authors $[11,12]$. Blood cultures were obtained from hospitalized patients with a fever of $\geq 38^{\circ} \mathrm{C}$ or other signs of severe infections admitted to $\mathrm{CHDZ} / \mathrm{C}$. The medical records of patients with blood cultures positive were reviewed for symptoms and signs, underlying medical disorders, and antimicrobial treatment. We included in the

*Corresponding author: Ta Ahoyo, Département du Génie de Biologie Humaine EPAC 01BP 2009 Cotonou, Benin, E-mail: taahoyo@yahoo.fr

Received May 13, 2013; Accepted July 18, 2013; Published July 22, 2013

Citation: Ahoyo TA, Yehouenou Pazou E, Baba-Moussa L, Attolou Gbohou A, Boco M, et al. (2013) Staphylococcus sciuri outbreak at Tertiary Hospital in Benin. J Med Microb Diagn 2: 126. doi:10.4172/2161-0703.1000126

Copyright: ( 2013 Ahoyo TA, et al. This is an open-access article distributed under the terms of the Creative Commons Attribution License, which permits unrestricted use, distribution, and reproduction in any medium, provided the original author and source are credited. 
present study 596 patients who had growth in blood culture one or more isolates of microorganism. Particular attentions have been paid to patients with S. sciuri. Two infections on the same patient are counted once. Because this study registered individual patient data, informed verbal consent was obtained by parents or guardians.

\section{Microbiology identification}

All blood samples referred by clinicians from hospitalized adult patients were systematically collected on BACTEC $^{\circledR}$ containing aerobic (BA) or anaerobic (BAA) resins. Bottles containing 8-12 $\mathrm{mL}$ of whole blood were incubated in BACTEC $^{\circledR} 9240$ instruments (Becton Dickinson, Meylan, France) for a standard 5-days incubation protocol or less if positive signal was detected. Positive blood cultures were subcultured on Columbia II agar base with 5\% sheep blood. The plates were examined after overnight incubation at $35^{\circ} \mathrm{C}$. Any colony that resembled staphylococci was subcultured and further tested. Preliminary identification of an isolate as a member of the $S$. sciuri group was based upon microscopically characteristics, positive catalase reaction, positive oxidase test, and resistance to novobiocin; according to established procedures by authors [13-15]. Tests for detection of others pathogens, such as Escherichia coli, Enterococcus, Pseudomonas and Candida albicans were done by conventional methods [16].

Antibiograms for selected bacteria (S. aureus, S. sciuri) were obtained by the disk diffusion method. Isolates were inoculated according to the recommendations of the National Committee for Clinical Laboratory Standards [17]. The following antibiotics were tested: PenicillinG, Ciprofloxacin, Tetracycline, Gentamicin, Kanamycin, Erythromycin, Trimethoprim-sulfamethoxazole, Chloramphenicol and Vancomycin. Heterogeneous resistance of $S$. aureus to Oxacillin was checked by the test of Cefoxitin $30 \mu \mathrm{g}$ and $30 \mu \mathrm{g}$ Moxalactam/Latamoxef on MuellerHinton agar according to (CA-SFM 2010) [18]. The resistance to cefoxitin categorized it as methicillin-resistant Staphylococcus. The double-disk (DD) synergy test was used for detection of ESBL in clinical E. coli strains as described by Jarlier et al. [19]. A potentiation of the zone of cefotaxime, ceftriaxone, ceftazidime, or aztreonam by clavulanic acid represented a positive test result and was indicative of the possible presence of an ESBL.

\section{Environmental surveillance cultures}

Environmental cultures were obtained from potential environmental sources, various hospital surfaces, and inanimate objects, such as floor areas, bed frames, over-bed tables, chairs, lockers, door handles, light switches, nurse call buttons, telephones, bathtubs, sinks, faucet, toilet seats, stands for infusion apparatus, intravenous pump buttons, mobile instrument tables, instruments, mobile monitor units, and sterilizing drums. The samples were taken with sterile cotton tipped swabs moistened with phosphate-buffered saline ( $\mathrm{pH}$ 7.2) and transported to the laboratory within immediately. The samples were weekly taken with sterile cotton tipped swabs moistened with phosphate buffered saline ( $\mathrm{pH}$ 7.2) and transported to the laboratory immediately. The swabs were inoculated into STS broth and agar as previously describe by Stepanovic et al. [14]. Cultures were not obtained from healthcare workers.

\section{The clonally relatedness}

The direct identification of bacteria by the MALDI-TOF/MS was serially processed in parallel of the routine protocol five days, a week at the laboratory of bacteriology of the Strasbourg University hospital from 15-Dec-2008 to 22-Dec-2008. The bacterial pellet was treated with the standard ethanol/formic acid protein extraction protocol for MALDI-TOF identification according to Mellmann et al. reported by
Moussaoui et al. [20]. Close relationship (at least at the genus level) was identified for log score comprised between 1.7 and 2.0 according to Prod'hom et al. [21], using BiflexIII mass spectrometer and Biotyper ${ }^{\mathrm{TM}}$, Flex-analysis ${ }^{\mathrm{TM}}$ softwares (Biotyper System, Bruker Daltonics ${ }^{\mathrm{TM}}$ ) for analysis of acquired data.

\section{Statistical analysis}

All statistics were performed by SPSS software 17.0. Contingency table analysis was done by $\chi^{2}$ test or two-tailed Fisher's exact test for categorical variables. A P-value of 0.05 was considered statistically significant.

\section{Results}

\section{Global results}

During the six months of continuous data monitoring, a total of 714 microorganisms' isolates were registered from 596 of the 13233 patients surveyed. Gram-positive accounted for $63 \%(n=451)$, Gram-negative $30 \%(n=214)$ and undetermined $7 \%(n=49)$. Staphylococci were the most frequently isolated pathogens; $E$. coli was also frequently isolated accounting for $50 \%$ of Enterobacteriaceae isolates. A summary of the different microorganisms isolated from blood during the study period was shown in Table 1. The administrative data were collected; the

\begin{tabular}{|c|c|c|c|}
\hline $\begin{array}{l}\text { Microorganismisolatedfr } \\
\text { om(blood) bacteremia }\end{array}$ & $\begin{array}{l}\text { Number } \\
\text { and } \%\end{array}$ & $\begin{array}{c}\text { Bacteremia related } \\
\text { to a vascular } \\
\text { catheter } \mathrm{N}(\%)\end{array}$ & Mortality \\
\hline CNS & $(229 / 714) 32$ & $129(52 \%)$ & $48(28 \%)$ \\
\hline Epidermidis & $(101 / 229) 44$ & 72 & $13(7.5 \%)$ \\
\hline S. sciuri & $(56 / 229) 24,5$ & 32 & $25(14.5 \%)$ \\
\hline Others CNS & $(72 / 229) 31,5$ & 25 & $10(5.8 \%)$ \\
\hline Staphylococcus aureus & $(122 / 714) 17$ & $71(29 \%)$ & $44(26 \%)$ \\
\hline Enterococcus & $(33 / 714) 4,5$ & Unknown & $16(9 \%)$ \\
\hline Streptococcus pneumonia & $(26 / 714) 3,5$ & Unknown & Unknown \\
\hline Enterobacteria & $(213 / 714) 30$ & $22(9 \%)$ & $32(18,6 \%)$ \\
\hline Escherichia coli & $(107 / 213) 50$ & 8 & $14(8.1 \%)$ \\
\hline Serratiamarcescens & $(57 / 213) 27$ & 10 & 2 \\
\hline Klebsiella pneumonia & $(28 / 213) 13$ & 2 & 7 \\
\hline Salmonella thyphi & $(14 / 213) 6,5$ & 0 & 1 \\
\hline Others enterobacteria & $(7 / 213) 3,5$ & 2 & 4 \\
\hline Pseudomonas aeruginosa & $(43 / 714) 6$ & $14(6 \%)$ & $17(9.8 \%)$ \\
\hline Candida albicans & $(20 / 714) 3$ & Unknown & Unknown \\
\hline anaerobicorganism & $(28 / 714) 4$ & $10(4 \%)$ & $4(2,3 \%)$ \\
\hline Total & 714 & $246 / 59641 \%$ & $172 / 59629 \%$ \\
\hline
\end{tabular}

NB. Gram-positive bacteria were most frequently encountered bacteria

Table 1: Frequency of microorganism isolated from Nosocomial bactereamia at CHDZ/C from June to December 2008.

\begin{tabular}{|l|c|c|c|}
\hline Diagnosis of patient & $\begin{array}{c}\text { Nosocomial } \\
\text { Bactereamia }\end{array}$ & Death (N) & $\%$ \\
\hline Skin and Soft Tissue Infection & 147 & 56 & 33 \\
\hline Catheter infection (long) & 145 & 23 & 13 \\
\hline Surgical Site Infection & 104 & 20 & 12 \\
\hline Catheter infection (short) & 101 & 18 & 10.5 \\
\hline Urinary tract infection & 42 & 18 & 10.5 \\
\hline Pneumonia & 23 & 15 & 8 \\
\hline Gastrointestinal System Infection & 21 & 12 & 7 \\
\hline Others & 13 & 10 & 6 \\
\hline Total & 596 & 172 & 100 \\
\hline
\end{tabular}

Mortality was the highest for patients with Skin and Soft Tissue Infection

Table 2: Clinical signs and underlying pathologies associated to Nosocomial bactereamia. 
number of hospitalizations days was 285600; the mean hospital stay was 10 days for others patients and 45 days for patients with bactereamia.

\section{Characteristics of patients with nosocomial bactereamia}

The diagnosis of bacteraemia has been established for 596 patients. All patients fulfilled the case definition of nosocomial bacteraemia. The mean age of the patient was 57 years (18-64); $55 \%$ of the patient had less than 40 years old and $21 \%<60$ years old. Sex ratio female $/$ male $=1 / 3$. Most of the patients have underlying diseases such as Skin and Soft Tissue Infection and others, presented in Table 2. Included patients had fever $t^{\circ}>38^{\circ} \mathrm{C}$ and C-reactive protein (CRP) was positive with values between $256 \mathrm{~g} / \mathrm{mL}$ and $4.105 \mathrm{~g} / \mathrm{mL}$ (100\%). Blood numeration showed hyper leukocytosis $>22000$ neutrophils $/ \mathrm{mm}^{3}$ in $70 \%$ (417) of cases and 22\% (131) cases where leukopenia $<3000$ neutrophils $/ \mathrm{mm}^{3}$. Inflammatory ( $80 \%)$ and anemia (32\%) were other criteria observed. Renal function and hepatic enzyme levels were normal.

Patient with Nosocomial bactereamia caused by $S$. sciuri accounted for 9.4\% (56/596), Skin and Soft Tissue Infection and intravenous catheter implantation were the two most predisposing factors (59\% and $57 \%)$ respectively. All except two patients had healthcare associated $S$. sciuri bacteraemia during hospitalization, all 54 patients had the first positive blood culture obtained more than $48 \mathrm{~h}$ after admission. The two patients with doubtful origin of bactereamia were referred from an over hospital. All patients received initial empirical therapy with 3 rd generation cephalosporins and metronidazole (500 mg 8-8 h). Initial antibiotics were ineffective in 15 patients. Better outcome was noticed in patients receiving initially effective antibiotic. Death arose for 25 patients (45\%).

\section{Frequency}

Nosocomial bacteraemia incidence rate was 2,51cases per 1000 patient-days (Table 2). The incidence rate in intensive care wards was 4.48 per 1000 patient-days. Fifty patients had polymicrobial infections. A total of $19 \mathrm{E}$. coli isolates with ESBL phenotype were recovered from 16 patients. Catheter was the commonest source of nosocomial bacteraemia $41 \%$. Deaths (of any cause) occurred in $29 \%$ (172) of patients with bacteraemia.

\begin{tabular}{|c|c|c|c|}
\hline \multicolumn{2}{|c|}{$\begin{array}{l}\text { Prevalence of patients infected and } \\
\text { prevalence of infections }\end{array}$} & \multicolumn{2}{|c|}{ Proportion of CNS isolate from patient } \\
\hline $\begin{array}{l}\text { Prevalence of } \\
\text { patients infected }\end{array}$ & $\begin{array}{l}4,5 \text { IC } 95 \% \\
{[3,8-5,2]}\end{array}$ & $\%$ of CNS & $32(229 / 714)$ \\
\hline $\begin{array}{l}\text { Prevalence of } \\
\text { infections }\end{array}$ & $\begin{array}{l}5.4 \% \text { (IC 95\% } \\
{[4.8 \%, 6.3 \%]}\end{array}$ & $\%$ S. sciuri among CNS & $24,5(56 / 229)$ \\
\hline Incidence & $\begin{array}{l}714 / 285600=2.51 \\
\text { cases per } 1000 \\
\text { patient-days }\end{array}$ & $\begin{array}{l}\text { Incidence of bloodstream } \\
\text { caused by S. sciuri }\end{array}$ & $\begin{array}{l}56 / 285600=0.2 \\
\text { cases per } 1000 \\
\text { patient-days }\end{array}$ \\
\hline \multicolumn{4}{|c|}{ The overall isolation rate of $\boldsymbol{S}$. sciuri in the hospital environment } \\
\hline \multicolumn{2}{|c|}{ Environmental samples (420) } & \multicolumn{2}{|l|}{$15 \%(63 / 420)$} \\
\hline \multicolumn{2}{|l|}{ Floors areas } & \multicolumn{2}{|l|}{$29 \%(18 / 63)$} \\
\hline \multicolumn{2}{|l|}{ Door Handle } & \multicolumn{2}{|l|}{$22 \%(14 / 63)$} \\
\hline \multicolumn{2}{|c|}{ Intravenous Pump Buttons } & \multicolumn{2}{|l|}{$14 \%(9 / 63)$} \\
\hline \multicolumn{2}{|l|}{ Faucet } & \multicolumn{2}{|l|}{$10 \%(6 / 63)$} \\
\hline \multicolumn{2}{|c|}{ Stands for infusion apparatus } & \multicolumn{2}{|l|}{$8 \%(5 / 63)$} \\
\hline \multicolumn{2}{|c|}{ Mobile instrument tables } & \multicolumn{2}{|l|}{$5 \%(3 / 63)$} \\
\hline \multicolumn{2}{|l|}{ Bed Frames } & \multicolumn{2}{|l|}{$5 \%(3 / 63)$} \\
\hline \multicolumn{2}{|l|}{ Chairs } & \multicolumn{2}{|l|}{$3 \%(2 / 63)$} \\
\hline \multicolumn{2}{|l|}{ Sterilizing drums } & \multicolumn{2}{|l|}{$3 \%(2 / 63)$} \\
\hline \multicolumn{2}{|l|}{ Nurse Call Buttons } & \multicolumn{2}{|l|}{$1 \%(1 / 63)$} \\
\hline
\end{tabular}

Table 3: Frequency of bloodstream infections at CHDZ/C during the study period.

\begin{tabular}{|l|l|l|l|l|}
\hline Staphylococcus & Methi S & Methi R Van S & Van R & Unkown \\
\hline S. aureus (N 122) & $62 \%(76 / 122)$ & $36 \%(44 / 122)$ & $1,6 \%(2 / 122)$ & $2(1.6 \%)$ \\
\hline $\begin{array}{l}\text { S. scuiri from } \\
\text { patients N (56) }\end{array}$ & $68 \%(38 / 56)$ & $32 \%(18 / 56)$ & $16 \%(9 / 56)$ & 0 \\
\hline $\begin{array}{l}\text { Environmental } \\
\text { S. scuiri N (63) }\end{array}$ & $46 \%(29 / 63)$ & $54 \%(34 / 63)$ & $33 \%(21 / 63)$ & 0 \\
\hline Total N (119) & $56 \%(67 / 119)$ & $44 \%(52 / 119)$ & $25 \%(30 / 119)$ & 0 \\
\hline
\end{tabular}

Methi S: Methicillin Sensitive; Methi R: Methicillin Resistant; Van S: Vancomycin Sensitive; VAN R: Resistant to Vancomycin

Table 4: Main resistance pattern observed among S. aureus and S. sciuri.

\begin{tabular}{|l|l|l|l|}
\hline Profile & $\begin{array}{l}\text { Clinical } \\
\text { isolates } \\
\mathbf{( 5 6 )}\end{array}$ & $\begin{array}{l}\text { Environment } \\
\mathbf{( 6 3 )}\end{array}$ & $\begin{array}{l}\text { MALDITOF/MS } \\
\text { reliable } \\
\text { identification }\end{array}$ \\
\hline $\begin{array}{l}\text { Profile 1: POGTeSX- } \\
\text { TER (43 isolates) }\end{array}$ & 18 & 25 & $\begin{array}{l}\text { Staphylococcus sciuri ssp } \\
\text { sciuri DSM 20345T Score } \\
2.389\end{array}$ \\
\hline $\begin{array}{l}\text { Profile 2: PTe SXTEV R } \\
\text { (26 isolates) }\end{array}$ & 9 & 17 & $\begin{array}{l}\text { Staphylococcus sciuri ssp } \\
\text { sciuri DSM 20345T Score } \\
2.031\end{array}$ \\
\hline $\begin{array}{l}\text { Profile 3: P Kan and } \\
\text { SXTR (25 isolates) }\end{array}$ & 15 & 10 & $\begin{array}{l}\text { Staphylococcus sciuri ssp } \\
\text { sciuri DSM 6671 Score 2.424 }\end{array}$ \\
\hline $\begin{array}{l}\text { Profile 4: P Te SXT R } \\
\text { (19 isolates) }\end{array}$ & 14 & 5 & $\begin{array}{l}\text { Staphylococcus sciuri ssp } \\
\text { carnaticus DSM15613Score } \\
2.038\end{array}$ \\
\hline $\begin{array}{l}\text { Profile 5: P OTe SXT V } \\
\text { R (4 isolates) }\end{array}$ & 0 & 4 & $\begin{array}{l}\text { Staphylococcus vitulinus DSM } \\
9931 \text { Score 1.962 }\end{array}$ \\
\hline $\begin{array}{l}\text { S. sciuri P SXT R } \\
\text { (2 isolates) }\end{array}$ & 0 & 2 & $\begin{array}{l}\text { No reliable identification Score } \\
1.415\end{array}$ \\
\hline
\end{tabular}

P: Penicillin G: Gentamycin; O: Oxacillin; G: Gentamycin; Te: Tetracycline; SXT: Trimethoprim Sulfametoxazole; E: Erythromycin; V: Vancomycin; R: Resistant

Profile 1: POGTeSXTE R: resistant to penicillin, Oxacillin, Gentamycin, tetracyclin, Trimethoprim, sulfametoxazole and Erythromycin.

Profile 2: P Te SXT E V R: resistant to Penicilling, Tetracyclin, Trimethoprimsulfametoxazole, Erythromycin and Vancomycin.

Profile 3: Resistant to PenicillinG kanamycin Trimethoprim- sulfametoxazole

Profile 4: Resistant to Tetracyclin, Trimethoprim, and sulfametoxazole.

Profile 5: Resistant to PenicillinG, Oxacillin, Tetracyclin, Trimethoprim, sulfametoxazole and Vancomycin

Table 5: Antimicrobial susceptibility patterns of $S$. sciuri isolates related to biotype.

\section{Isolation of $S$. sciuri from patients' samples and environment}

Coagulase Negative Staphylococcus represented 32\% of blood isolates microorganisms; the proportion of S. sciuri was $24.5 \%$ and represented $8 \%$ of all patients' isolates. The overall isolation rate of $S$. sciuri in the hospital environment was $15 \%$. In total, 25 strains of S. sciuri were recovered along in pure culture. On the other hand, 24 strains of S. sciuri were co-isolated with other enterobacteria (Escherichia coli, Klebsiella pneumonia), Enterococcus, Pseudomonas aeruginosa, Candida spp and unidentified Gram negative bacteria. The distribution of isolates from various samples is presented in Table 3. Only samples in which S. sciuri were at pure/major culture of aerobic flora ( $\geq 90 \%$ UFC) have been considered for further investigation.

\section{Antimicrobial susceptibility}

The Table 4 show the antimicrobial susceptibility patterns for S. aureus isolates and S. scuiri isolates. Antimicrobial susceptibility for S. sciuri: out of 119 isolates tested (56 from patients and 63 from hospital environment), all the isolates were resistant to Penicillin and Trimethoprim-sulfamethoxazole and were susceptible to Ciprofloxacin and Chloramphenicol while $25(21 \%)$ were resistant to kanamycin. Fifty two strains (44\%), were resistant to Oxacillin, 65 (55\%) to Gentamicin, $90(76 \%)$ to Tetracycline and $30(25 \%)$ were resistant to Vancomycin. 


\section{Mass spectra result}

Considering their different antibiograms, four distinct strains were thought to be involved in the outbreak of $S$. sciuri during the period study. Based on the protein mass patterns, bacterial strains can be clustered hierarchically by Biotyper ${ }^{\mathrm{TM}}$. The result generated by this approach including five different $S$. sciuri isolates, with four isolates of Staphylococcus vitullus presented only in hospital environment and two undermined isolates. One predominant biotype was present in 18 patients and represents $40 \%$ of environment isolates; this type was resistant to Penicillin, Oxacillin, Gentamycin, Tetracycline, Trimethoprim-Sulfamethoxazole, and Erythromycin. The results are presented by Table 5 .

\section{Discussion}

The aim of this study was to determine the prevalence and characterize S. scuiri members among CNS causing bacteraemia in a tertiary Hospital in Benin. We identified a high proportion of $S$. sciuri $24.4 \%$ among CNS causing bacteraemia at CHDZ/C hospital during the period study; despite the fact that $S$. sciuri in patients was reported for the first time in Benin. Infections due S. sciuri in human are wellknown problems [7,9]; however, the incidence of $S$. sciuri in humans was reported for urinary tract only [8]. In the year prior to this study, S. sciuri was detected in $2 \%$ of children who attended pediatric unit of CHDZ/C hospital. Although CNS has been recovered from inpatients with bacteraemia [22,23], the present study is the first report describing $S$. sciuri as the cause of this condition at Benin. The isolation from human blood is unusual; we presumed that S. sciuri found in the blood was clinically significant and not a contaminating organism because; first, all patients fulfilled the case definition of sepis, second the blood culture were obtained upon clinical signs and symptoms of infection and third, S. sciuri was recovered along in pure culture, from the blood of twenty five patients. The fact that $S$. sciuri has been associated with infections such as endocarditis [24], urinary tract infection [8] and wound infections $[25,26]$ illustred the possible implication of this bacterium in bloodstream infections. Therefore, we considered the isolated strain of S. sciuri as one of the causative agents of bacteraemia of polymicrobial aetiology.

The results presented showed a relatively high rate of colonization by S. sciuri of the hospital environment tested; the floor area accounted for $29 \%$ of the total number of isolates recovered and corroborated the finding of authors [27] and Intravenous Pump Buttons 14\%. The medical personnel were not investigated in this study. We believe this finding add evidence to support the hypothesis that the hospital environment may served as reservoirs of nosocomial pathogens and vectors for cross transmission in the hospital.

In the present study, most of $S$. scuiri isolates were collected from patients in the surgical ward and the ICU. In these wards, patient are exposed to great antibiotic pressure, furthermore, many of these patients are particularly vulnerable to infection because they are immunocompromised or have an easy avenue of access for bacteria. In addition improper ward routine practices during wound dressing, such as unnecessary exposure to the atmosphere while other activities such as sweeping, dusting, bedmaking, drawing of curtains and movements are going on, may have contributed to the Nosocomial transmission of S. sciuri.

Intravenous catheter related infection was considered to be a possible portal of entry of bacterium during bacteraemia $[28,29]$, fifty seven percent ( 32 out 56 ) had central venous catheter at onset bacteraemia, the mainly reason of $S$. scuiri acquisition seem to be the presence of catheter, skin disease and the lack of hygiene due to poor access to potable water.

In the study there were eight patients with polymicrobial bacteraemia who had no obvious port of entry; this suggests likelihood of an intra-abdominal origin S. sciuri bacteraemia.

The MALDITOF/MS and susceptibility typing of antimicrobial agents tested presented a good correlation. The presence of five types with one dominant in our sample, suggests an outbreak with multidrug resistant $S$. sciuri which was paralleled by a small cluster of $S$. sciuri cases caused by an endemic, nosocomial strain.

The bacteria were highly resistant to the Penicillin, to Gentamicin, to Trimethoprim-sulfamethoxazole, Tetracycline and Vancomycin antibiotic family. This might be due to the fact that certain classes of antibiotics are easily accessible and frequently used by the patients without medical prescription in Benin according to Ahoyo et al. [30]. In view of emerging Vancomycin resistance, restriction of Vancomycin for empiric therapy of late-onset infections has been advocated to reduce Vancomycin exposure.

The result showed that $S$. sciuri subspecies sciuri was most frequently isolated from the hospital environment, followed by subspecies carnaticus and subspecies vitullus. Although the same distribution pattern of $S$. sciuri subspecies was reported by Marsou et al. [6] for clinical isolates of this bacterium.

The present study suggests that $S$. sciuri subspecies sciuri is a relatively frequent colonizing organism in hospital environment in Benin. In summary, S. sciuri can easily spread within the healthcare setting and offers a sobering reminder of the need to maintain high standards of hygiene.

The outbreak described here was contained by implementing a multifaceted infection control intervention, with special emphasis of bedside, alcohol-based hand disinfection. Since all the measures were undertaken simultaneously, we cannot define which of the measure was the most important.

The present study does not provide support for routine screening of blood samples for these bacteria. Neverless the results presented suggest that further prospective studies are required to determine the importance of bacteria of the S. sciuri group as blood pathogen, particularly in hospitalized patients.

In conclusion, an outbreak of nosocomial S. sciuri bacteraemia occurred on CHDZ/C hospital in Benin; our findings suggest an associated pattern of environmental contamination and patient infection. The present study clearly showed that S. sciuri may colonize skin and, moreover, may be involved in the pathogenesis of an infection as serious as bactereamia. The high rates of isolation we established, strongly suggest that bacteraemia caused by $S$. sciuri is only sporadic and, most probably, transient. More detailed studies of this organism are required and serious efforts to eliminate it from the hospital should be launched.

\section{References}

1. Kloos WE, Bannerman TL (1994) Update on clinical significance of coagulasenegative staphylococci. Clin Microbiol Rev 7: 117-140.

2. Pfaller MA, Herwaldt LA (1988) Laboratory, clinical, and epidemiologica aspects of coagulase-negative staphylococci. Clin Microbiol Rev 1: 281-299.

3. Shittu AJ, Lin J, Morrison D, Kolawole D (2004) Isolation and molecular characterization of multiresistant Staphylococcus sciuri and Staphylococcus 
Citation: Ahoyo TA, Yehouenou Pazou E, Baba-Moussa L, Attolou Gbohou A, Boco M, et al. (2013) Staphylococcus sciuri outbreak at Tertiary Hospital in Benin. J Med Microb Diagn 2: 126. doi:10.4172/2161-0703.1000126

Page 5 of 5

haemolyticus associated with skin and soft-tissue infections. J Med Microbiol 53: 51-55.

4. Jain A, Agarwal J, Bansal S (2004) Prevalence of methicillin-resistant, coagulase-negative staphylococci in neonatal intensive care units: findings from a tertiary care hospital in India. J Med Microbiol 53: 941-944.

5. Horii T, Suzuki Y, Kimura T, Kanno T, Maekawa M (2001) Intravenous catheter related septic shock caused by Staphylococcus sciuri and Escherichia vulneris. Scand J Infect Dis 33: 930-932.

6. Marsou R, Bes M, Boudouma M, Brun Y, Meugnier H, et al. (1999) Distribution of Staphylococcus sciuri subspecies among human clinical specimens, and profile of antibiotic resistance. Res Microbiol 150: 531-541.

7. Hedin G, Widerstrom M (1998) Endocarditis due to Staphylococcus sciuri. Eur J Clin Microbiol Infect Dis 17: 673-675.

8. Stepanovic S, Jezek P, Vukovic D, Dakic I, Petras P, et al. (2003) Isolation of members of the Staphylococcus sciuri group from urine and their relationship to urinary tract infections. J Clin Microbiol 41: 5262-5264.

9. Stepanovic S, Dakic I, Djukic S, Lozuk B, Svabic-Vlahovic M, et al. (2002) Surgical wound infection associated with Staphylococcus sciuri. Scand J Infect Dis 34: 685-686.

10. Hanberger H, Diekema D, Fluit A, Jones R, Struelens M, et al. (2001) Surveillance of antibiotic resistance in European ICUs. J Hosp Infect 48: 161 176 .

11. Pittet D, Tarara D, Wenzel RP (1994) Nosocomial bloodstream infection in critically ill patients. Excess length of stay, extra costs and attributable mortality. JAMA 271: 1598-1601.

12. Nosocomial Infection National Surveillance Service Surveillance of hospita acquired bacteraemia in English hospitals 1997-2002. Public Health Laboratory Service

13. Freney J, Kloos WE, Hajek V, Webster JA, Bes M, et al. (1999) Recommended minimal standards for description of new staphylococcal species. Int J Syst Bacteriol 49: 489-502.

14. Stepanovic S, Vukovic D, Savic B, Svabic-Vlahovic M (2000) Staphylococcus sciuri: recommendation for simple identification. New Microbiol 23: 201-205.

15. Vernozy-Rozand C, Mazuy C, Meugnier H, Bes M, Lasne Y, et al. (2000) Staphylococcus fleuretti sp. nov., isolated from goat's milk cheeses. Int J Syst Evol Microbiol 50: 1521-1527.

16. Freney J, Renaud F, Hansen W, Bollet C (2000) Précis de Bactériologie Clinique. (1stedn), Editions ESKA, Paris

17. National Committee for Clinical Laboratory Standards (2002) Performances standards for antimicrobial susceptibility testing. Twelfth informational supplement. NCCLS document M100-S12. National Committee for Clinical Laboratory Standards, Wayne, $\mathrm{Pa}$.

18. Tristan A, Ying L, Bes M, Etienne J, Vandenesch F, et al. (2003) Use of multiplex PCR to identify Staphylococcus aureus adhesins involved in human hematogenous infections. J Clin Microbiol 41: 4465-4467.

19. Jarlier V, Nicolas M, Fournier G, Philippon A (1988) Extended broadspectrum $\beta$-lactamases conferring transferable resistance to newer ßlactam agents in Enterobacteriaceae: hospital prevalence and susceptibility patterns. Rev Infect Dis 10: $867-878$

20. Moussaoui W, Bouakaze C, Prevost G (2009) Applications de la spectrométrie de masse MALDI-TOF à l'identification bactérienne. Bulletin de la Société Française de Microbiologie 24: 293-302.

21. Prod'hom G, Bizzini A, Durussel C, Bille J Greub G (2010) Matrix-assisted laser desorption ionization-time of flight mass spectrometry for direct bacterial identification from positiveblood culture pellets. J Clin Microbiol 48: 1481-1483.

22. Bogado I, Sutich E, Krapp A, Marchiaro P, Marzi M, et al. (2001) Methicillin resistance study in clinical isolates of coagulase-negative staphylococci and determination of their susceptibility to alternative antimicrobial agents. $\mathrm{J} \mathrm{Appl}$ Microbiol 91: 344-350.

23. Von Eiff C, Peters G, Heilmann C (2002) Pathogenesis of infections due to coagulase-negative staphylococci. Lancet Infect Dis 2: 677-685.

24. Cutting KF, Harding KG (1994) Criteria for identifying wound infection. J Wound Care 3: 198-201.

25. Wallet F, Stuit L, Boulanger E, Roussel-Delvallez M, Dequiedt $P$, et al. (2000) Peritonitis due to Staphylococcus sciuri in a patient on continuous ambulatory peritoneal dialysis. Scand J Infect Dis 32: 697-698.

26. Coimbra DG, Almeida AG, Júnior JB, da Silva L, Pimentel BJ et al. (2011) Wound infection by multiresistant Staphylococcus sciuri identified by molecular methods. New microbiol 34: 425-427.

27. Park KH, Kim SH, Song EH, Jang EY, Lee EJ, et al. (2010) Development of bacteremia or fungaemia after removal of colonized central venous catheters in patients with negative concomitant blood cultures. Clin Microbiol Infect 16: 742-746.

28. Talon D (1999) The role of the hospital environment in the epidemiology of multi-resistant bacteria. J Hosp Infect 43: 13-17.

29. Dakic' I, Morrison D, Vukovic' D, Savic' B, Shittu A, et al. (2005). Isolation and Molecular Characterization of Staphylococcus sciuri in the Hospital Environment. J Clin Microbiol June: 2782-2785.

30. Ahoyo TA, Fatombi KJ, Boco M, Aminou T, Dramane K, et al. (2011) Impact de la qualité de l'eau et de l'Assainissement sur la Santé des enfants en milieu préurbain au Bénin ; cas des zones sanitaires de Savalou-Bantè et DassaGlazoué. Médecine tropicale 71: 1-5.

This article was originally published in a special issue, Allergy \& Immunology

handled by Editor. Dr. Edwin Dias, Rajiv Gandhi University, India 